\title{
"Kom je algauw bij mannen terecht": Alles verandert van Kristien Hemmerechts (2015) als feministische herschrijving
}

\begin{abstract}
The article analyses the novel Alles verandert (Everything changes, 2015) by Flemish author Kristien Hemmerechts in the context of "feminist rewriting". At the same time "feminist rewriting" is being introduced as a functional literary strategy that enables the writer to challenge and adapt the existing literary canon. Summing up the existing scholarship on feminist/women's rewriting, the article makes a plea to include "feminist rewriting" in the (not only) Dutch literary-analytical toolbox in order to get a better understanding of such practices and their intentions.
\end{abstract}

Keywords: Kristien Hemmerechts, Alles verandert, Disgrace, feminist rewriting, postcolonial rewriting, canon, classics, Dutch literature.

\section{Inleiding}

In een episode van The Tracey Ullman's Show verhoort de comédienne, verkleed als politieagente, een man die slachtoffer is geweest van een overval. De agente is duidelijk niet geïnteresseerd in zijn kant van het verhaal en in plaats daarvan vraagt ze hem wat hij aan heeft gehad en of hij niet denkt dat hij de dader heeft geprovoceerd met zijn kleding en zijn 'provocatieve' houding.

"Alles verandert als je het geslacht van de personages verandert. Het verhaal is weinig realistisch, en dat hoeft ook niet, maar met een vrouw van middelbare leeftijd in de rol van Humbert en een twaalfjarige Lolito wordt het een farce, een satire of burleske" (Hemmerechts 2015: 47). Zo beschrijft professor Iris Verdonck, het hoofdpersonage uit Alles verandert, de werking van het TransSexLit principe - een uitvinding van Verdonck - op Lolita van Vladimir Nabokov. Precies 
dezelfde dynamiek zien we in de sketch van Ullman. Zowel de roman, die ik in dit artikel wil bespreken, als de video maakt gebruik van dezelfde strategie, een strategie die we 'feministische herschrijving' kunnen noemen. Dat wil zeggen dat de rollen worden omgedraaid waardoor een tot nu toe onzichtbare of genegeerde machtsdynamiek ontmaskerd wordt. Ook is het binnen deze strategie mogelijk om een bestaand verhaal te her-vertellen vanuit het perspectief van een personage dat in de oorspronkelijke tekst zonder stem is gebleven. Ullman laat in de video heel duidelijk zien op welke manier vrouwen in onze maatschappij veel te vaak worden behandeld. Haar satirische uitbeelding maakt er een punt van om de rollen om te draaien, en daardoor iets te laten zien wat meestal onopgemerkt blijft omdat het zo vanzelfsprekend is, of als normaal wordt beschouwd. Maar als we de rollen omdraaien krijgt een vrijwel normale scène uit het dagelijkse leven (van een vrouw) plotseling een andere dimensie waardoor we beseffen hoe oneerlijk de gegenderde rolverdeling in onze maatschappij is. Feministische herschrijving als literaire strategie doet precies hetzelfde maar met gecanoniseerde literaire teksten.

In dit artikel wil ik de roman Alles verandert waarin Kristien Hemmerechts Disgrace van J.M. Coetzee (1999; In Ongenade, 2007) herschrijft in de context van zgn. feministische herschrijving bespreken en de roman plaatsen binnen het kader van Hemmerechts' feminisme en maatschappelijke betrokkenheid. Zodoende zal ik ook aandacht besteden aan de literaire canon vanuit het feministische en postkoloniale oogpunt. Ik zal verder stilstaan bij een aantal recensies van de roman om aan te tonen dat kennis van zulke geëngageerde literaire strategieën binnen het Nederlandstalige literaire veld grotendeels afwezig is terwijl dit wel noodzakelijk is voor het begrijpen van deze roman en het gehele oeuvre van Hemmerechts.

\subsection{Feministische herschrijving en de Nederlandstalige literatuur}

Het is niet de eerste keer dat Hemmerechts met feministische herschrijving experimenteert. Al in De vrouw die de honden eten gaf (2014) probeerde ze een verhaal te herschrijven vanuit een ander, vrouwelijk perspectief. In het personage van Odette gaf ze de stem aan Michelle Martin, de ex-vrouw van de pedofiele seriemoordenaar Marc Dutroux. Sommige reacties op haar herschrijving (zie bijv. De Wolf 2014) duiden op onbegrip voor wat Hemmerechts met haar boek probeert te doen. Namelijk een andere visie tonen van een bekend verhaal waarvan het vaste waardeoordeel al ingebed is in de samenleving.

Hemmerechts, die in 1986 met een proefschrift promoveerde over Jean Rhys, auteur van een van de meest bekende postkoloniale herschrijvingen, ${ }^{1}$ was niet de

1 Rhys publiceerde in 1966 de roman Wide Sargasso Sea als een feministische en post- (of anti-)koloniale herschrijving van Jane Eyre (1847) door Charlotte Brontë. 
eerste die is begonnen met feministische/vrouwelijke herschrijving. Al lang voor haar zijn er vrouwen geweest die een gecanoniseerd werk (door een mannelijke schrijver) gingen herschrijven. Een van de vroegste voorbeelden van deze literaire strategie dateert al van 1752 wanneer Charlotte Lennox met The Female Quixote; or, The Adventures of Arabella de klassieker Don Quixote van Miguel de Cervantes Saavedra ${ }^{2}$ herschrijft. In de Nederlandse literatuur kennen we daar ook een aantal voorbeelden van. In 1976 heeft Hella S. Haasse Een gevaarlijke verhouding of Daal-en-Bergse brieven gepubliceerd waarin ze het verhaal verder vertelt van de markiezin de Merteuil uit Les liaisons dangereuses (1782, Gevaarlijke hartstochten). Er is ook het debuut van Nelleke Noordervliet, Tine of De dalen waar het leven woont (1987), waarin ze Multatuli's Max Havelaar herschrijft vanuit het perspectief van Havelaars vrouw. "Niet bepaald een innovatieve kijk op Tine", schrijft Judit Gera (Gera 2010: 84) maar "[...] het geeft de pen (en daarmee de macht van het vertellen en van het focaliseren) in de hand van een vrouw in plaats van de vier mannelijke vertellers" (Gera 2010: 86). Sleuteloog (2002) van opnieuw Hella S. Haasse waarin ze haar eigen werk - de novelle Oeroeg uit 1948 - herschrijft valt meer onder de noemer van postkoloniale herschrijving (zie Vitáčková 2008) maar ook hier wordt duidelijk een 'mannenverhaal' herschreven tot een 'vrouwenverhaal'. Mijns inziens is de meest geslaagde poging tot feministische herschrijving in de Nederlandse literatuur het fictiedebuut van Elsbeth Etty Maak jezelf maar klaar (2007) waarin Etty De ontdekking van de hemel (1992) her-vertelt vanuit het perspectief van Ada, die in de roman van Mulisch min of meer tot een baarmoeder op pootjes wordt gereduceerd.

\section{Theoretische omkadering}

Herschrijven van eerdere werken is een postmodern procedé, "both symptom and an active instrument" (Moraru 2001: 9). Feministische (en bij uitbreiding postkoloniale) herschrijving vormt echter een aparte categorie en vereist daardoor ook een aparte aanpak. Postkoloniale en feministische herschrijving zijn literaire praktijken die uit een specifiek moment in de samenleving voortkomen (Moraru 2009: XIV). Aangezien ze allebei vanuit de positie van maatschappelijk activisme komen, zijn ze meer en anders dan een intelligent en intellectueel aangepakte (maar niet politiek gemotiveerde) intertekst.

Het lijkt veel productiever om over feministische herschrijving in de context van écriture feminine na te denken, een denkwijze die ernaar streeft om het vrouwelijke te herwaarderen. Vanaf de jaren ' 60 van de vorige eeuw zijn feministische theoretici en critici bezig met de manieren waarop vrouwen schrijven en

${ }^{2}$ In het Spaans El Ingenioso Hidalgo Don Quijote de la Mancha, gepubliceerd in 1605 en 1615. 
lezen als tegenstelling tot de fallogocentrische orde waarin de man centraal staat. Vrouwen zijn toen systematisch literair werk gaan produceren dat het patriarchale systeem deconstrueert en zijn bestaan als het enige mogelijke systeem (van taal, geschiedenis, filosofie, literatuur...) ter discussie stelt. "It takes a thoroughgoing familiarity with male figureheads of Western culture to recognize the intertextual games played by all these writers; their work shows that a resistance to culture is always built, at first, of bits and pieces of that culture, however they are disassembled, criticized, and transcended" (Jones 1981: 14). Sindsdien komt de kwestie van anders denken en herschrijven van gecanoniseerde teksten regelmatig voor. Een belangrijk recent werk over dit onderwerp is Transforming Memories in Contemporary Women's Rewriting van Liedeke Plate (2011) waarin ze de rol van herschrijven in de hedendaagse feministische literatuur vanaf de jaren ' 70 analyseert en in de context van memory studies plaatst. Plate beschouwt vrouwelijke of feministische herschrijving namelijk als een manier om het verleden anders te herinneren en beschrijft het als "[...] feminist approach to the past confident that change is possible and that it will be brought about by changing the stories which shape cultural foundation myths and thus human existence" (Plate 2010: 8).

Naast Plate is er, voor zover ik weet, maar één boek met de term feminist rewriting in de titel. In Spite of Plato. A Feminist Rewriting of Ancient Philosophy van Adriana Cavarero (1995), met een uitgebreid voorwoord van Rosi Braidotti, biedt heel belangrijke theoretische inzichten in wat feministische herschrijving is, waarom het belangrijk is en hoe het precies werkt. Cavarero beweert dat vrouwelijke karakters uit mannelijke teksten door hedendaagse feministische lezers toegeëigend kunnen en moeten worden. In haar voorwoord beschrijft Braidotti de strategie die Cavarero toepast als doelbewuste diefstal. Volgens haar neemt de auteur discursieve beelden terug uit de patriarchale beeldvorming om ze vervolgens een nieuwe betekenis en context te kunnen geven. Een dergelijke toe-eigening vormt een betekenisvolle bijdrage aan het feministische debat over vrouwelijke subjectiviteit (Braidotti in Cavarero 1995: XIII).

[...] precisely because there is no canon other than the masculine one and because even the few female figures that are available in texts are the creation of man, Cavarero proposes that feminist readers of today reappropriate these figures and reread them in the light of their existence, we thus end up with embodied feminist subjects revisiting the textual site of feminine figures, and walking off with new knowledge claims and meanings (Braidotti in Cavarero 1995: XIII-XIV).

Cavarero ontdoet vrouwelijke personages van lagen van mogelijke interpretaties. Eenmaal los van de zeer beperkte betekenissen, die aan vrouwelijke personages worden toegewezen, leest ze deze personages opnieuw als vrouw die andere vrouwen in de tekst leest. 


\subsection{Postkoloniale herschrijving}

Zo'n strategie doet denken aan wat postkoloniale herschrijving al heel lang doet. Het doel van feministische en postkoloniale herschrijving is namelijk hetzelfde: om onderliggende machtsstructuren bloot te leggen en een patriarchale en/of koloniale tekst (en taal!) te ontmaskeren. Vrouwen delen de ervaring van gekoloniseerde mensen omdat ze ook hun ervaringen noodgedwongen in de taal van de onderdrukker moeten uitdrukken (Ashcroft e.a. 2003: 172). Op die manier worden ze genoodzaakt om binnen een dominante traditie tegen deze traditie te schrijven.

\subsection{De canon}

Precies daarom vinden feministische en postkoloniale critici het bestaan van de canon problematisch. Lilian S. Robinson noemt het ontstaan van de canon een "gentlemen's agreement" waarmee ze naar de uitsluiting van vrouwen, mensen van kleur en lagere klassen verwijst (Robinson 1983: 84). Judith Fetterley noemt de Amerikaanse canon eenvoudigweg mannelijk (Fetterley 1978: XII). Anderen beweren dat de canon een product is van een traditie die gedomineerd wordt door mannen, en als referentie wordt gebruikt voor esthetische waarde van een tekst, terwijl esthetische waarde allesbehalve universeel is, noch gevestigd is in de tekst (Barrett 1980).

Dat wil natuurlijk niet zeggen dat de hele Westerse canon verbannen moet worden. Wat ik wel zou willen voorstellen is om meer aandacht te geven aan hoe canons ontstaan en hoe ze staande worden gehouden. Canons zijn normatief en veroorzaken bij vele lezers gevoelens van acculturatie en ontheemding (Mukherjee 2013: 7-8). Vrouwelijke lezers maken vaak ontgendering mee. Dit aspect van vrouwelijk lezen heeft ook Hemmerechts besproken in haar pamflet De man, zijn penis en het mes (2008). Om sommige gecanoniseerde werken te kunnen appreciëren moeten vrouwen namelijk tegen zichzelf lezen, zichzelf ontkennen.

Wat betekent het voor vrouwen om omringd te worden door voorstellingen in woord en in beeld die ze stuitend vinden, maar die op veel bewondering kunnen rekenen? Als ze niet in staat zijn die bewondering te delen, ligt dat vast aan hen. Hun gevoel voor humor is onvoldoende ontwikkeld. Of hun gevoel voor literatuur, voor kunst. Hun preutsheid resulteert in cultureel analfabetisme. Elke vrouw moet twee vrouwen worden: zij die zich aanpast [...] en zij die er het hare van denkt (Hemmerechts 2008: 12).

Geïnspireerd door Spivak pleit ik voor een vernieuwde canon met "[...] a bit of the old masters in new perspectives, women's literature, black women's literature, a glimpse of Afro-America, the literature of gendered homosexuality, of migrant ethnicity, of the exploited in struggle" (Spivak 2015: 308). Feministi- 
sche herschrijving is een uiterst geschikte literaire strategie om de oude gecanoniseerde werken, the old masters, in een ander perspectief te zetten en daardoor aspecten zichtbaar maken die anders, o.a. door gecodificeerde interpretaties van zo'n gecanoniseerde tekst, onzichtbaar zouden blijven.

Feministische en postkoloniale critici zijn het erover eens dat deze gecodificeerde interpretaties van gecanoniseerde teksten net zo problematisch zijn als sommige boodschappen in deze teksten.

[...] a canon is produced by the intersection of a number of readings and reading assumptions legitimized in the privileging hierarchy of a 'patriarchal' or 'metropolitan' concept of 'literature'. This offers the possibility of reconstructing the canon, and not simply replacing it in an 'exchange of texts', since both discourses recognize that to change the canon is to do more than change the legitimized texts. It is to change the conditions of reading for all texts (Ashcroft e.a. 2003: 173).

Feministische herschrijving is een manier om de leesomstandigheden van gecanoniseerde werken te veranderen. "Yet rewriting is not only an oppositional gesture, challenging the ideology of canonical texts and the perspectives they embody by 'writing back' to it [...]. It is, paradoxically, also a counter memorial discursive practice that activates canonicity. Rewriting keeps the canon alive, as well as the idea of the canon", schrijft Plate (Plate 2010: 131) die heel haar vijfde hoofdstuk aan de complexe verhouding tussen hedendaagse vrouwelijke herschrijving en het canoniseringsproces wijdt (Plate 2010: 130-155).

\section{Alles verandert als feministische herschrijving}

Dit artikel is een voorstel om Alles verandert te beschouwen als Hemmerechts' poging om precies dit te doen, namelijk de setting van het lezen van gecanoniseerde teksten, en de gestandaardiseerde en gecodificeerde betekenissen daarvan, te veranderen en daardoor de canon te herzien. Of tenminste een alternatieve leeswijze aan te bieden voor een tekst die al twee decennia een onaantastbare status heeft als een van de meest belangrijke romans van einde twintigste eeuw (Van der Vlies 2010: IX).

Disgrace vertoont ongetwijfeld tekens van mannelijke seksualiteit die als problematisch, en door de vrouwelijke lezer vervreemdend, ervaren kunnen worden. Hemmerechts duidde daar al eerder op in De man, zijn penis en het mes. Ze betwist de literaire kwaliteiten van Disgrace niet maar wil het mogelijk maken om zo'n gecanoniseerd werk te bespreken.

Ik heb zijn cruciale passages heel vaak gelezen, en dan denk ik nog steeds: is het nou ironie van Coetzee of niet? Ik vermoed eigenlijk van niet. Tegelijkertijd weet ik: het maakt voor de literatuur niets uit. Dat boek heeft zoveel aanzien, je mag er alleen nog maar met veel respect over praten. Dat irriteert me. Toch moet het mogelijk zijn er een debat over te voeren (Smid 2015). 
Met Alles verandert maakt ze een interessant punt in haar kritiek van gewelddadige mannelijke seksualiteit en haar pleidooi om gecanoniseerde werken bespreekbaar te maken. Volgens Sellers kan feministische herschrijving in twee categorieën verdeeld worden - "an act of demolition, exposing and detonating the stories that have hampered women" en "a task of construction - of bringing into being enabling alternatives" (Sellers 2001: 30). Hemmerechts combineert beide in Alles verandert. Ze gaat nog een stapje verder dan haar voorgangsters en voorgangers en ze is ook veel explicieter in haar studie van machts- en genderverhoudingen. Zoals ze in haar pamflet schrijft, is het soms nodig om een derde vrouw te worden - "(D)ie zegt het hardop. Of ze schrijft het" (Hemmerechts 2008: 12). De vraag "Waarom maakt het zoveel uit of een bepaalde rol in een verhaal door een man dan wel door een vrouw wordt ingevuld?" speelt een centrale rol in de roman - in de tekst en de metatekst. Hemmerechts herschrijft Coetzees roman weliswaar niet vanuit het perspectief van de studente, noch vanuit het oogpunt van Davids dochter, wat de voor de hand liggende keuzes zouden zijn geweest voor een feministische herschrijving. Maar door het gender van het hoofdpersonage te veranderen ontbloot Hemmerechts de anders onzichtbare machtsverhoudingen en diep geankerde gegenderde rolpatronen.

\subsection{His-story, her-story}

De hoofdpersoon van Disgrace is de 52-jarige, twee keer gescheiden professor literatuur aan de universiteit van Cape Town David Lurie. Zijn seksuele behoeftes worden vervuld met wekelijkse bezoeken aan prostituee Soraya, een oplossing waar hij heel tevreden mee is, aldus de eerste zin van de roman (Coetzee 2000: 1). Zijn passie wordt pas aangewakkerd door zijn (bruine) studente Melanie die hij begint te achtervolgen en met wie hij een affaire begint. De gevoelens zijn echter niet wederzijds, David zelf beschrijft in de bekende zin van de roman hun sekspartij als "Not rape, nor quite that" (Coetzee 2000: 25) en na een tijdje dient Melanie een officiële klacht in. Als gevolg van deze klacht en het opeenvolgende onderzoek van de tuchtcommissie, waarvoor David weigert zijn schuld te bekennen is hij gedwongen om de universiteit te verlaten. Hij zoekt zijn toevlucht in de Oost-Kaap waar zijn dochter Lucy op een boerderij woont en werkt, in samenwerking met haar buurman Petrus. David helpt Lucy met de boerderij en in de hondenopvang die Lucy runt. Hij werkt ook als vrijwilliger bij de Animal Welfare Clinic samen met Bev Shaw met wie hij later een verhouding zal beginnen.

Op een dag dringen drie mannen het huis binnen waar ze Lucy verkrachten, David in de wc opsluiten en in brand steken. Al de honden in de opvang worden doodgeschoten, op de buldog Katy na. Tijdens dit alles is buurman Petrus nergens te zien. Als Lucy en David enkele tijd later op een feestje bij Petrus de jongste van de mannen zien wordt duidelijk dat Petrus deze jongen goed kent en hem 
beschermt. Door deze ontmoeting escaleert de spanning tussen vader en dochter nog verder, David begrijpt namelijk niet waarom Lucy haar verkrachting niet wil aangeven en waarom ze daarover zwijgt. Nadat zijn gestolen auto teruggevonden wordt, keert David terug naar Kaapstad waar hij zijn appartement geplunderd terugvindt. Hij ontmoet ook de ouders van Melanie en biedt zijn excuses aan voor wat hij de familie heeft aangedaan. Als Bev hem belt dat er een ontwikkeling is bij Lucy gaat David terug naar de boerderij en komt te weten dat Lucy zwanger is.

In Hemmerechts' herschijving wordt de 52-jarige professor aan de universiteit van Antwerpen Iris Verdonck verliefd op de Poolse Erasmus studente Agnieszka. Tot ze Agnieszka ontmoette leidde de gescheiden Iris een tevreden leven gericht op haar carrière. Net zoals David had ze een gemakkelijke oplossing voor haar seksuele behoeftes door wekelijkse bezoeken aan dr. Wouters die haar in zijn praktijk met verschillende dildo's bevredigde. Als de dokter haar vertelt dat hij met pensioen gaat en haar niet meer zal kunnen helpen is Iris radeloos. Tegen beter weten in begint ze Agnieszka te achtervolgen en knoopt een onevenwichtige verhouding met haar aan. Als Agnieszka zelfmoord probeert te plegen en Iris van seksuele intimidatie beschuldigd wordt moet ze voor de tuchtcommissie verschijnen. Net zoals David erkent ze de feiten maar voelt daar geen spijt over. Als ze met verplicht verlof de universiteit verlaat besluit ze om naar haar vervreemde zoon te gaan die in Arendonk op een villa van een rijke diplomaat past met de hulp van Somalische vluchtelingen Imamu en zijn vrouw Aminia. Net als bij David en Lucy is de verhouding tussen Iris en haar zoon Peter niet hartelijk en is er afstand en ongemak voelbaar tussen hen.

Op een dag dringen drie Somalische vrouwen de villa binnen en verkrachten Iris met een gebroken glasdildo. Ook tijdens deze aanranding is de opzichter Imamu nergens te bespeuren. Hemmerechts verduidelijkt haar keuze om niet alle rollen om te draaien:

Wat je in een boek kunt doen, is de rollen omdraaien. Ik wilde kijken wat er gebeurt als 'hij' een 'zij' is. De vraag was hoever ik kon gaan met die rolomkering. [...] Als ik het helemaal had gespiegeld, zouden de drie vrouwen Iris' zoon hebben verkracht. Dat leek me niet te doen. Drie keer gedwongen een erectie? Arme Iris was daardoor de pineut (Smid 2015).

Volgens Saskia Pieterse volgt Hemmerechts hier echter Coetzee omdat op deze manier alleen de vrouw slachtoffer is. "De man als slachtoffer van seksueel geweld - een van de grote taboes in canonieke macho-literatuur - komt niet aan orde" (Pieterse 2015).

Iris wordt opgenomen in het ziekenhuis maar weigert een aanklacht in te dienen. Als ze later een van de vrouwen terugziet bij de villa zegt Peter (wiens naam aan Coetzees Petrus doet denken) dat ze het met rust moet laten. Iris vertrekt naar Antwerpen waar ze haar huis bewoond vindt door kennissen van haar dochter. Ze ontmoet ook de ouders van Agnieszka, die ooit als gastarbeiders in België hebben gewerkt en probeert zich te verontschuldigen voor haar acties, net zoals David 
geprobeerd heeft om te doen tijdens het ongemakkelijke etentje bij Melanies ouders in George (Coetzee 2000: 169-174). Eenmaal terug in Arendonk ziet Iris dat Imamu, die duidelijk bevriend was met de verkrachters, in status is gegroeid, opzichter van de manege is geworden en de baas speelt. Ook is Imamu's tweede vrouw uit Somalië gekomen en Aminia, die hem geen kinderen kon geven, wordt opzij geduwd. Iris biedt Aminia aan om mee te gaan naar Antwerpen en als ze weigert vertrekt ze alleen.

\subsection{Feministische herschrijving in praktijk}

Alles verandert is duidelijk een weerspiegeling van Disgrace. Hemmerechts gaat in haar tekst tot in detail om deze precies neer te zetten, schetst dezelfde scenario's en gebruikt vaak zelfs dezelfde uitdrukkingen. "That is where he ought to end it. But he doesn't", constateert David (Coetzee 2000: 18). "Daar zou het moeten eindigen, maar het eindigt niet", geeft Iris toe (Hemmerechts 2015: 37).

Soms kiest Hemmerechts voor precies het tegenovergestelde, zoals bij het gender van de hoofdpersonage. Terwijl Melanie bruin is (van gemengde afkomst dus) en als "the dark one" door David wordt beschreven (Coetzee 2000: 18) is de blonde Agnieszka juist geportretteerd als bleek en bijna doorzichtig. Wel draagt Melanie een gele regenjas en Agnieszka een geel zwempak. Allebei David en Iris worden geobsedeerd door de schoonheid van hun jonge studentes en zijn zonder twijfel schuldig aan objectivering. "Je bent zo mooi. Ik zou jou ingelijst aan de muur willen hangen", zegt Iris (Hemmerechts 2015: 44). David beaamt deze objectivering met zijn stelling: "Because a women's beauty does not belong to her alone. It is a part of the bounty she brings into the world. She has a duty to share it" (Coetzee 2000: 16).

Melanie en Agnieszka worden beschreven als kinderen (Coetzee 2000: 20; Hemmerechts 2015: 44), Iris gebruikt ook bijvoorbeeld veel verkleinwoorden als ze met/over Agnieszka spreekt (Hemmerechts 2015: 25, 29, 33, 43, 44). Zowel David als Iris zijn bewust van hun machtspositie en maken daar ook gebruik van, bijv. door de studente uit te nodigen voor een lunch bijvoorbeeld, of door ze te helpen spijbelen. "She is behaving badly, getting away with too much; [...] But if she has got away with much, he has got away with more; if she is behaving badly, he has behaved worse" (Coetzee 2000: 28). Op een gegeven moment zoeken beide studentes toevlucht in het huis van hun professoren waar ze gehuisvest worden in de kamer van hun kinderen wat de dubieuze positie van leraar-ouder-minnaar nog benadrukt.

Hemmerechts is er ook in geslaagd om de specifieke lokale elementen van Zuid-Afrika naar een Belgische context te vertalen. Zo is de kosmopoliete Kaapstad Antwerpen geworden. De paranoia van de blanke bevolking na het eind van apartheid is weerspiegeld in de gespannen sfeer tijdens de Europese vluch- 
telingencrisis die juist in 2015/2016 culmineerde. Hemmerechts' keuze voor een Poolse Erasmusstudente is een slimme oplossing voor de dubbel onevenwichtige verhouding tussen de blanke David en bruine Melanie, aangezien Poolse gastarbeiders en migranten in België vaak met xenofobie en vooroordelen te maken hebben (zie bijv. Sterckx 2016). Agnieszka komt natuurlijk niet toevallig uit Siematycze, een stad in het Oosten van het land waar bijna de gehele volwassen bevolking naar België is getrokken om daar te werken. Iris vermeldt in deze context vaak ook haar Poolse schoonmaakhulp Yannick (Hemmerechts 2015: 26).

\subsection{De grenzen van vrouwelijke seksualiteit}

Iris lijkt regelmatig tegen de grenzen te botsen van wat vrouwen veroorloofd wordt op seksueel gebied. Ze schaamt zich dat ze tegen betaling seksueel bevredigd wordt door dr. Wouters. Als ze dat toch bekent krijgt ze een 'geschrokken' reactie van de Deense collega, die zelf zegt gebruik te maken van prostituees (Hemmerechts 2015: 17). Als Iris seks heeft met de Deense collega of haar ex-man wordt er geen aandacht geschonken aan haar gevoelens noch behoeftes. Ze beschrijft zichzelf dan ook als "sekspop" (17) en een "homp vlees" (124). Over de mannelijke seksualiteit beweert ze: "Het maakt hun geen moer uit of een vrouw geniet of niet. Ze willen klaarkomen. Ze gebruiken een vrouw om zich af te rukken" (125).

Het veranderen van het gender laat ons frappante verschillen zien tussen wat vrouwen en mannen veroorloofd wordt. "Hoe is het mogelijk dat iemand die haar hele leven mannelijk misbruik heeft aangekaart, nu precies hetzelfde doet?" wordt Iris gevraagd tijdens de zitting van de tuchtcommissie (Hemmerechts 2015: 91). Herhaaldelijk wordt er nadruk gelegd op het feit dat het juist Iris overkomt en wordt de vraag gesteld hoe haar gedrag in haar feministische politieke opvattingen past (Hemmerechts 2015: 90).

Het gebruik van dildo's in de roman, niet alleen voor de verkrachting van Iris maar ook voor het plezier van Iris (en Agnieszka), werd duidelijk als een storend element ervaren door de mannelijke recensenten. Dat duidt opnieuw op de dubbele standaarden wat mannelijke en vrouwelijke seksualiteit betreft in onze samenleving. Vullings beschrijft Iris in zijn recensie als "geobsedeerd door dildo's" (Vullings 2015). De dildo noemt hij "lustvoorwerp" en tegelijk stelt hij een veel passender titel voor Hemmerechts roman voor, namelijk "Much ado about a dildo" (Vullings 2015). Ook Hellemans kan het niet zonder commentaar voorbij laten gaan en schrijft: "Dildo's zijn het geliefkoosde speeltje van Hemmerechts' hoofdpersonage en dat zal de studente dus geweten hebben" (Hellemans 2015).

De dildo is wel een belangrijk symbool in het boek aangezien het de seksuele bevrijding en emancipatie van Iris met mannelijkheid en patriarchaat verbindt. Het is geen toeval dat er in de praktijk van dokter Wouters een groot portret 
hangt van Sigmund Freud en van zijn grootvader. Net zoals het niet willekeurig is dat alles uit de hand begint te lopen nadat de dokter zijn praktijk heeft gesloten, Iris niet meer kan ontvangen en haar seksualiteit dus zonder de mannelijke begeleidende hand is. De dildo symboliseert de fallogocentrische orde die Iris zo uitgesproken bekritiseert maar waar ze tegelijk niet aan kan ontsnappen. Door Agnieszka dan met een dildo te bevredigen, en niet op een andere, non-penetrerende manier, onderwerpt Iris haar ook aan deze patriarchale orde waar de fallus centraal staat.

\subsection{Iris en de canon}

Tegen het einde van de roman mag Iris terugkeren naar de universiteit. Maar niet meer om het vak TransSexLit te geven dat, na twintig jaar, wordt afgeschaft. Iris wordt namelijk gevraagd om les te geven juist over de gecanoniseerde auteurs. Er vindt de volgende conversatie tussen Iris en Cécile plaats:

- Ik denk dat jonge mensen vandaag behoefte hebben aan traditionele waarden. We leven in vluchtige, verwarrende tijden. We moeten hun iets solides bieden, een ankerpunt. Ik had Shakespeare in gedachten, Milton, Byron, Donne, misschien ook Shelley of Keats, Wordsworth, Blake.

- Allemaal mannen.

- Als je het over traditionele waarden hebt, kom je algauw bij mannen terecht (Hemmerechts 2015: 242-243).

Uiteindelijk besluit Iris om niet terug te keren. Ze gaat terug naar Antwerpen maar niet meer naar de universiteit. Daar is ze klaar mee, vertelt ze aan Aminia. "I have finished with the university", proclameert David in Disgrace (Coetzee 2000: 174). Op die manier neemt ze duidelijk afstand van de gecanoniseerde (mannelijke) klassiekers. Als Iris ze niet mag uitdagen en bekritiseren (zoals Hemmerechts zelf voorstelt) kiest ze er liever voor om zich er helemaal van te distantiëren.

\section{Receptie}

De roman heeft nogal uiteenlopende recensies ontvangen. Wat voor mijn pleidooi voor de feministische herschrijving van belang is, is het gedeeltelijke onbegrip van de recensenten. Het ongemak waarmee de seksualiteit van Iris werd ervaren is al vermeld. Typerend lijkt ook de verwarring wat termen en beeldvorming rondom deze recensies betreft. Hellemans noemt Hemmerechts "dé Nederlandstalige SM-schrijfster bij uitstek" (Hellemans 2015). De verder heel positieve review door Persis Bekkering werd begeleid door een foto van transseksueel model Andreja Pejic. De beeldvorming van de recensie van Christophe van Gerrewey speelt op dezelfde foutieve noot met de titel Transgender. 
Een van de weinige recensenten die de intenties van Hemmerechts lijken te hebben begrepen is Saskia Pieterse. $\mathrm{Zij}$ noemt Alles verandert een "droogkomisch commentaar op In ongenade" (Pieterse 2015) en trekt duidelijk een verband tussen de roman en het eerdere pamflet. Tegen het einde van haar stuk uit ze haar ontgoocheling dat Hemmerechts de grenzen niet verder heeft gepusht en dat de roman vooral van bewondering voor Coetzee getuigt en zijn roman dus verder canoniseert - hetzelfde punt dat Plate in haar boek noemt (Plate 2010: 131).

\section{Conclusie}

Van Gerrewey vraagt zich in zijn recensie af: "Waarom een literair auteur zo'n pas op de plaats zou willen maken, door een klassiek geworden roman te gebruiken zonder dit experiment nauwkeurig op te zetten en met gigantische impasse tot gevolg: het blijft een raadsel" (Van Gerrewey 2016: 121). Dit artikel is een poging om aan te tonen dat ze zich juist heel goed bewust is van de status van de roman en deze niet noodzakelijk probeert te 'ontheiligen', zoals Smid voorstelt, maar wel tracht in een andere context te plaatsen en van de gestandaardiseerde betekenissen te ontdoen, zodat we nieuwe betekenissen aan deze tekst kunnen koppelen (Braidotti in Cavalero 1995: XIV).

De uiteindelijke tekst is niet een 'gigantische impasse' maar een onderdeel van Hemmerechts' pleidooi tegen seksisme in de literatuur en het gewelddadige mannelijke in gecanoniseerde werken. Om dit te kunnen inzien is echter kennis van het werk en activisme van Hemmerechts nodig, en verstand van literaire herschrijf-technieken. Alles verandert zou waarschijnlijk niet als een losstaande literaire tekst kunnen werken maar ik durf te beweren dat dit ook niet de bedoeling is geweest. Hemmerechts is namelijk heel duidelijk in haar intenties en heeft haar roman ook aan Coetzee opgedragen. Alles verandert is een interessante en nuttige bijdrage tot de discussie over de canonieke status van zekere literaire werken en het gesprek over de grenzen van mannelijke en vrouwelijke seksualiteit - niet alleen in literatuur.

\section{Bibliografie}

Ashcroft, Bill, e.a. (2003): The Empire Writes Back: Theory and Practice in Post-Colonial Literatures. London: Routledge.

Barret, Michèle (1980): Women's Oppression Today: Problems in Marxist Feminist Analysis. London: New Left Books.

Bekkering, Persis (2015): “Als je van een 'hij' een 'zij' maakt”. De Volkskrant 5.09.2015, laatst geraadpleegd op 18.05.2017<https://www.volkskrant.nl/boeken/als-je-van-een-hij-een-zij-maakt a4135083>. 
Cavarero, Adriana (1995): In Spite of Plato: A Feminist Rewriting of Ancient Philosophy. Cambridge: Polity Press.

Coetzee, John M. (2000): Disgrace. London: Penguin.

De Wolf, Ludwig (2014): "Nieuwe boek Hemmerechts niet te koop in Paard van Troje Gent". De Redactie 27.01.2014, laatst geraadpleegd op 10.03.2017 <http://deredactie.be/cm/vrtnieuws/ cultuur\%2Ben\%2Bmedia/kunsten/1.1849607>.

Fetterley, Judith (1978): The Resisting Reader: A Feminist Approach to American Fiction. Vol. 247. Bloomington: Indiana University Press.

Gera, Judit (2010): “Tine: stem of tegenstem?” Over Multatuli 32:64, 83-88.

Hellemans, Frank (2015): "Kristien 'The woman you love to hate' Hemmerechts wordt 60". Knack 26.08.2015, laatst geraadpleegd op 17.05.2017<http://www.knack.be/nieuws/boeken/kristienthe-woman-you-love-to-hate-hemmerechts-wordt-60/article-normal-597399.html>.

Hemmerechts, Kristien (2008): De man, zijn penis en het mes. Amsterdam: Querido's Uitgeverij BV. Hemmerechts, Kristien (2014): De vrouw die de honden eten gaf. Breda: De Geus.

Hemmerechts, Kristien (2015: Alles verandert. Breda: De Geus.

Jones, Ann Rosalind (1981): „Writing the body: Toward an understanding of l'Ecriture Feminine”. Feminist Studies 7:2, 247-263.

Moraru, Christian (2001): Rewriting: Postmodern Narrative and Cultural Critique in the Age of Cloning. Albany NY: SUNY Press.

Mukherjee, Ankhi (2013): What is a Classic?: Postcolonial Rewriting and Invention of the Canon. Stanford CA: Stanford University Press.

Pieterse, Saskia (2015): "In de ban van de penis". De Reactor 1.11.2015, laatst geraadpleegd op 1.11.2015 <http://www.dereactor.org/home/detail/in_de_ban_van_de_penis $>$.

Plate, Liedeke (2010): Transforming Memories in Contemporary Women's Rewriting. New York: Springer.

Robinson, Lillian S. (1983): "Treason our text: Feminist challenges to the literary canon". Tulsa Studies in Women's Literature 2:1, 83-98.

Sellers, Susan (2001): Myth and Fairy Tale in Contemporary Women's Fiction. London: Palgrave Macmillan.

Smid, Ally (2015): „John M. Coetzee ontheiligen doe je zo”. Trouw 25.08.2015, laatst geraadpleegd op 7.02.2017<https://www.trouw.nl/home/john-m-coetzee-ontheiligen-doe-je-zo a6a6458f $>$.

Spivak, Gayatri Chakravorty (2012): Outside in the Teaching Machine. London: Routledge.

Sterckx, Jo (2016). Beelden van Polen en Midden-en Oost-Europa in de Nederlandse cultuur. Poznań: Wydawnictwo Naukowe UAM.

Ullman, Tracey (2017): “What were you wearing?" - The Tracey Ullman's Show: Season 2, Episode 6 Preview - BBC One, laatst geraadpleegd op 10.03.2017<https:/www.youtube.com/ watch? $\mathrm{v}=51-$ hepLP8J4\&t $=2 \mathrm{~s}>$.

Van der Vlies, Andrew Edward (2010): JM Coetzee's Disgrace. London: Continuum.

Van Gerrewey, Christophe (2016): "Transgender. Alles verandert van Kristien Hemmerechts". DWB 2, 118-121.

Vitáčková, Martina (2008): "Postkoloniale herschrijving van land van herkomst in het werk van Hella S. Haasse". In: Zdenka Hrnčířová e.a. (red.), Praagse Perspectieven 5. Praha: Universitas Carolina Pragensis, 399-404 (= Handelingen van het Regionaal Colloquium Neerlandicum van Midden-Europa aan de Karelsuniversiteit op 20, 21 en 22 september 2007).

Vullings, Jeroen (2015): "We zijn dildokinderen". Vrij Nederland 1.10.2015, laatst geraadpleegd op 18.05.2017 <https://www.vn.nl/kristien-hemmerechts-wij-zijn-dildokinderen>. 